DOI 10.37882/2223-2982.2020.06.17

\title{
СТРУКТУРНАЯ ТИПОЛОГИЯ АББРЕВИАТУРНОГО КОМПОНЕНТА В СУБДИСКУРСЕ РАДИООБМЕНА ПИЛОТ - АВИАДИСПЕТЧЕР
}

\section{STRUCTURAL TYPOLOGY OF THE ABBREVIATION COMPONENT IN THE SUBDISCOURSE OF PILOT - AIR TRAFFIC CONTROLLER RADIO EXCHANGE}

\section{T. Malkovskaya} T. Ryabova

Summary: This article is devoted to abbreviated components of printed meteorological messages when conducting radio communications in aviation. Radio exchange is considered as a subdiscourse of professional discourse in the sphere of air traffic control. On the basis of quantitative and structural analysis of the lexical component of weather reports, abbreviations typical for pilot - air traffic controller communication are classified, and structural types of abbreviations are identified and described. The authors conclude that the use of abbreviations in printed meteorological messages is dictated by the nature of institutional discourse and provides radio exchange to be informative, concise and unambiguous. In addition to its scientific value, the analysis is of practical significance, since it is in demand when teaching professionally oriented aviation English.

Keywords: institutional discourse, radio exchange subdiscourse, meteorological messages, abbreviations, codified abbreviations, structural typology of English abbreviations, aviation English.
$\Pi$ рофессионально ориентированный подход к обучению иностранному языку предполагает тщательное изучение языкового материала конкретной сферы коммуникации. Инвентаризация средств выражения структурно-синтаксических и прагмалингвистических особенностей профессионального дискурса позволит расширить знания о языковых средствах и правилах общения в типичных ситуациях и избежать ошибок, которые могут привести к коммуникационному сбою. Это особенно актуально для таких сфер профессионального общения, в которых успех коммуникации предполагает не только выполнение обязанностей, но и обеспечивает безопасность коммуникантов. Примером может служить сфера, регулируемая строгими конвенциональными ограничениями, - организация воздушного движения (ОрВД).

Несмотря на достаточное количество работ, посвященных изучению институционального дискурса, особенности профессионального дискурса пользователей воздушного пространства, в частности, лексический
Мальковская Татьяна Александровна

К.филол.н., дочент, Краснодарское высшее военное авиачионное училище летчиков tatjynka@bk.ru

Рябова Татьяна Васильевна

К.филол.н., Краснодарское высшее военное авиационное училище летчиков tryabova_61@mail.ru

Аннотация: Данная статья посвящена аббревиатурным компонентам печатных метеорологических сообщений при ведении радиообмена в авиации. Радиообмен рассматривается как субдискурс профессионального дискурса сферы организации воздушного движения. На основе количественного и структурного анализа лексического компонента формализованных текстовых метеосводок в работе классифицированы сокращения, характерные для общения пилот - авиадиспетчер, выявлены и описаны структурные типы аббревиатур. Авторы приходят к выводу о том, что использование аббревиатур в воздушном радиообмене продиктовано характером институционального дискурса и обеспечивает сочетание информативности, краткости и однозначности высказывания. Проведенный анализ помимо научной ценности имеет практическую значимость, поскольку востребован при обучении профессионально ориентированному авиационному английскому языку.

Ключевые слова: институциональный дискурс, субдискурс радиообмена, метеорологические сообщения, аббревиатуры, кодифицированные сокращения, структурная типология английских аббревиатур, авиационный английский язык.

аспект текстов метеорологических сводок, передаваемых на борт в печатном формате открытого текста, остаются наименее изученными. Актуальность данной работы состоит в необходимости изучения англоязычных аббревиатур в специальных текстах с целью их описания и инвентаризации. Объектом исследования является аббревиатурный компонент субдискурса радиообмена, функционирующий в жанре метеорологических сообщениях в текстовом формате. Структурная типология английских аббревиатур в печатных текстах метеосообщений в режиме общения пилот-авиадиспетчер представляет предмет исследования. Цель данного исследования заключается в изучении и описании особенностей структурных типов аббревиатур в дискурсе радиообмена пилот - авиадиспетчер на материале печатных текстов метеосообщений.

Научная новизна работы определяется материалом исследования, а именно текстовые сообщения, которые передаются на борт самолета по средствам системы ACARS - Aircraft Communications Addressing and 
Reporting System (адресно-отчетная система авиационной связи). Выделены и описаны структурные типы аббревиатур субдискурса радиообмена (СР) в малоизученных текстовых метеорологических сообщениях.

Материалом послужил корпус английских сокращений (215 единиц), собранный методом целенаправленной выборки из документа Международной организации гражданской авиации (ИКАО) 8400 «Сокращения и коды ИКАО» (Doc 8400 ICAO Abbreviations and Codes) [1], текстов-образцов метеосводок, представленных в документах ИКАО 8896 «Руководство по авиационной метеорологии» (ICAO Doc 8896 AN/893) [2] и в Приложении 3 к Конвенции о международной гражданской авиации «Метеорологическое обеспечение международной аэронавигации» (ICAO Annex 3 Meteorological Service for International Air Navigation) [3], а также текстов реальной коммуникации интернет-ресурсов. Исследование проводилось методом целенаправленной выборки, лингвистического наблюдения, описания и классификации языковых явлений, а также методом структурного анализа и количественной обработки данных.

В нашей работе мы используем термины «сокращение» и «аббревиатура» как синонимы, понимая под этим «единицу устной или письменной речи, созданной из отдельных (не всех) элементов звуковой или графической оболочки некоторой развернутой формы (слова или словосочетания), с которой данная единица находится в определенной лексико-семантической связи» [4, с. 100].

Вслед за М.А. Ярмашевич признаем необходимость разграничения аббревиатур, которые являются элементами языка и закреплены в его системе, и сокращениями, которые появились в речи под влиянием определенных условий коммуникации, особенно профессиональной, но так и не стали самостоятельными словами [5].

Мы полагаем, что институциональный характер СР определяет принципы отбора и употребления языковых средств, которыми оперируют участники коммуникативной деятельности

Выделение конститутивных признаков дискурса, раскрытие социально-ситуативных особенностей и коммуникативной направленности текстов остается за рамками данного исследования. Однако мы считаем необходимым пояснить употребление термина «субдискурс радиообмена».

Дискурс понимается нами как «вербализованная речемыслительная деятельность, включающая в себя не только собственно лингвистические, но и экстралингвистические компоненты» [6, с.194].

Противопоставляя типы дискурса по типологии участников общения, мы принимаем точку зрения В.И. Карасика о том, что институциональный дискурс «есть специализированная клишированная разновидность общения между людьми, которые могут не знать друг друга, но должны общаться в соответствии с нормами данного социума» [7, с. 195].

Рассматривая профессиональный дискурс как род статусно-ориентированного дискурса, можно предположить, что он, в свою очередь, подразделяется на более узкие сферы, «частные разновидности», субдискурсы [8], которые могут отличаться по формату общения, но объединяться общей целью.

Радиообмен рассматривается нами как субдискурс профессионального дискурса сферы ОрВД, и представляет собой целенаправленную деятельность коммуникантов, организованную в соответствии с документально зафиксированными правилами и стандартами, принятыми в этой сфере. Коммуникативной целью общения пилот-авиадиспетчер является успешный обмен информацией между участниками для обеспечения безопасного и эффективного воздушного движения.

Каждая профессиональная разновидность распадается на жанровые составляющие, разнообразие которых определяется важностью общения для конкретного социума (В.И. Карасик, В.Е. Чернявская, С.А. Данилова и др.).

К жанрам субдискурса радиообмена пилот-авиадиспетчер мы относим жанр метеосообщений.

Согласно документам ИКАО, эти сообщения подразделяются на категории: а) местная регулярная сводка (METAR, METAR TREND); б) специальная метеорологическая сводка по аэродрому (SPECI, SPECI TREND); в) информация о возникновении определенных явлений погоды по маршруту полета, которые могут повлиять на безопасность полетов воздушных судов на малых высотах (AIRMET); г) информация о фактическом или ожидаемом возникновении явлений погоды по маршруту, которые могут повлиять на безопасность полета воздушных судов (SIGMET); д) метеорологическая информация для воздушных судов, находящихся в полете (D-VOLMET); е) сообщения службы автоматической передачи информации в районе аэродрома (D-ATIS). K разряду сообщений о погоде можно отнести и сообщения (NOTAM), содержащие, в частности, сообщение об опасных погодных условиях.

Информация о погоде может быть передана летчику в процессе радиообмена двумя способами: по средствам радиосвязи при прямом контакте с диспетчером по запросу либо при прослушивании информации, транслируемой на определенной частоте, либо по дву- 
сторонней системе передачи данных «диспетчер-пилот» посредствам текстовых сообщений.

Институциональность дискурса в данном жанре реализуется в полном устранении личностного начала участников. Пилот обозначает интенцию запроса информации действием выхода на определенную частоту для прослушивания или почтения сообщения на экране или распечатке. В текстовых сообщениях, в соответствии со стандартами информационного обмена, используется общепринятый прототипный формат данных для обеспечения функциональной совместимости при обмене информации.

Отличительной особенностью открытых текстов метеообщений является использование кодифицированных сокращений. Кодификация представлена использованием аббревиатур и профессиональных кодов. Использование буквенно-числовых кодов не ставит целью скрыть эту информацию от посторонних, но диктуется коммуникативными ценностями СР - краткость, точность, однозначность. В открытом текстовом формате метеосообщений функцию кода выполняют сокращения, которые используются в соответствии с документом ИКАО 8400 «Сокращения и коды ИКАО» [1]. Кроме этого, последовательность передаваемых элементов также закреплена документально (ICAO Annex 3, Meteorological Service for International Air Navigation [3]).

По мнению ученых, аббревиация - это результат информационной оптимизации сообщения, который выражается в редукции ряда элементов в лексической единице, несущих минимальную информационную нагрузку. Таким образом, устраняются коммуникационные «помехи», и сообщение принимает более адекватную и экономную форму передачи $[9$, с.9].

Широкое использование аббревиатур в текстах метеосообщений продиктовано как лингвистическими, так и экстралингвистическими факторами. Закон экономии речевых усилий лежит в основе эволюции языка: передача максимально возможного объема информации за единицу времени остается основным критерием его коммуникативной роли. «Тенденция к сжатости находит свое выражение в насыщенности сокращениями, использовании кодового способа передачи информации, высокой реккурентности эллиптических предложений» [10, с 5]. С другой стороны, увеличение потока информации и разработка технических средств ее передачи требуют изменения формы средств выражения. Надежный способ передачи данных особенно важен в авиации. Основным каналом связи летчик-диспетчер остается голосовая радиосвязь, но возросшая интенсивность воздушного движения, увеличившийся объем необходимых в полете данных, наличие факторов, препятствующих успешной коммуникации (помехи в эфире, человече- ский фактор) привели к внедрению новой системы передачи сообщений, доступных пользователям в текстовом формате. Одним из секторов применения этой технологии является получение метеорологических сводок погоды.

Жанр метеосообщений, в частности, и субдискурс радиообмена в целом, характеризуется своеобразным аббревиатурным пространством, в котором большинство сокращений не приобретает характеристик самостоятельных единиц языка, а образуются и функционируют как знаки с высоким информационным потенциалом.

Проблемой классификации аббревиатур занимались разные исследователи (Д.И. Алексеев, Т.И. Арбекова, О.С. Ахманова, В.В. Борисов, Е.А. Дюжикова, М.Д. Смирнова и др.). В нашей работе мы используем классификацию, подложенную М.А. Ярмашевич, которая выделяет лексические, собственно графические и графо-лексические сокращения, которые, в свою очередь, делятся на подтипы [5].

Проведенный анализ не выявил лексических аббревиатур, обладающих всеми признаками знаменательных слов. Анализ корпуса выборки показал, что самая многочисленная группа представлена собственно графическими аббревиатурами (190), в то время как группа графико-лексических сокращений состоит всего из 25 сокращений. Это объясняется функционированием сокращенных форм только в формате письменного текста.

Количество букв в составе аббревиатур варьируется от одной до семи. Логично было бы предположить, что двух- и трехкомпонентные аббревиатуры должны составить основную группу сокращений, так как однокомпонентные, во-первых, несут минимальную опознавательную информацию, следовательно, их значение надо запоминать, во-вторых, начальная буква многих слов терминологического поля «Метеорологическое обеспечение полетов» совпадает. Многоэлементные единицы, хотя и просты в опознавании, но менее удобны с утилитарной точки зрения. Количественный анализ подтвердил это предположение: двух- и трехкомпонентные сокращения представлены 148 примерами, остальные группы вместе - 67 аббревиатурами. Семикомпонентная подгруппа состоит всего лишь из двух сокращений SNOWTAM - special NOTAM about hazardous conditions due to snow; TSUNAMI - tsunami. TSUNAMI, хотя и совпадает с прототипом, может считаться компонентом аббревиатурного поля СР и с точки зрения оформления на письме, и функций, присущих полноправной лексической единице.

К собственно графическим сокращениям относятся аббревиатуры - знаки, функция которых замещать слова или группы слов. Они «живут» только в письменной речи, 
а при необходимости произнесения, заменяются полными прототипами. Графические аббревиатуры могут быть образованы как от отдельных слов, так и от словосочетаний и предложений.

Образовательной моделью по способу сокращения является усечение (финальное VC - vicinity либо медиальное - усечение средней части CLD - cloud). Преобладающий консонантный принцип усечения «свидетельствует о большей различительной силе и информационной значимости согласных по сравнению с гласными» [9, с 22].

Проведенный анализ показывает, что аббревиатурному процессу подвергаются как самостоятельные (BECMG - becoming, COND - condition, HVY - heavy, MIS missing, SCT - scattered), так и служебные (BTN - between, WI - within) части речи.

Собственно графические аббревиатуры отдельных слов представлены знаками, состоящими из одной буквы $N$ - north, а также двух AC - altocumulus, трех SLW slow, четырех FCST - forecast, пяти HURCN - hurricane, шести RDOACT - radioactive компонентов.

В группе двухкомпонентных примеров выделяется подгруппа из 7 единиц, которые являются усеченными вариантами слов французского языка, и эта аббревиатура присваивается соответствующему английскому слову mist (En.) - BR - brum (Fr.); smoke - FU, hail - GR, patches $B C$, dust/sand whirls - PO, small hail and/or snow pellets - GS, shallow - MN. В этом случае сокращение соотносится C прототипом через обозначаемый предмет.

Референция объекта и сокращения также может транслироваться через синонимическую пару sea - marine $M A R$ - at sea.

Особенностью компрессии в СР является сокращение именных, объектных и атрибутивных словосочетаний, среди которых выделяются модели:

а) буквенных инициальных аббревиатур, в которых:

- представлены все элементы словосочетания ТОС - top of clouds WS - wind shear; NC - no cloud. К этой группе, в частности, относятся название организаций, предоставляющих информацию о погоде VAAC - volcanic ash advisory center; MWO - meteorological watch office, либо аэродромные службы RFFS - rescue and firef fighting service;

- происходит элиминация одного или нескольких слов: IR - ice on runway; DP - dew point temperature. Несмотря на то, что в первом случае эллипсу подвергается служебное слово, а во втором - знаменательное, в обоих случаях их отсутствие не приводит к искажению смысла, а уменьшает семантическую нагрузку и количественно сокращает новую единицу. Инициальные сокращения одного из элементов прототипной единицы и элиминация остальных ( $H$ - significant wave height; $N$ - no distinct tendency), а также использование в качестве обозначения произвольной буквы, не выделяемой в исходной единице ( $P$ - maximum value of wind speed or runway visual range; $W$ - sea-surface temperature), свидетельствует скорее о предварительной договорённости участников общения, и позволяет рассматривать их как семиотические

единицы профессионального кода;

б) финального или медиального усечения одного из элементов и эллипса остальных: PL - ice pellets; DR - low drifting; BLO - BELOW clouds; VAL - in valley; EMBD - embedded in a layer;

в) эллипса одного из элементов без сокращения главного слова: TOP - cloud top; BASE - cloud base;

г) инициальной аббревиации и усечения TCU - towering cumulus; OTP - on top; ARP - air report; NCD - no cloud detected;

д) полного слова (предлога) и с инициального сокращения существительного INC - in cloud.

В поле зрения исследования попал пример сокращения предложения Aerodrome is closed due to snow - SNO$C L O$, состоящий из усеченных прототипов слов, несущих основную информационную нагрузку.

Структура собственно графических и графико-лексических аббревиатур совпадает. Отличие заключается в возможности звуковой реализации последних и их способности вступать в системные отношения. В зависимости от произношения, буквенного или звукового, они подразделяются на алфабетизмы и акронимы. Акронимы представлены следующими моделями:

- инициальная аббревиация (ATIS - automatic terminal information service; TAF - terminal aerodrome forecast);

- усечение и инициальная аббревиация (METAR meteorological air report);

- усечение и эллипс одного или нескольких элементов (SIGMET - significant meteorological report; SPECI - aerodrome special meteorological report; NOTAM notice to airmen);

- усечение слов французского языка (vol (flight) и météo (meteorological data) VOLMET - meteorological information for aircraft in flight);

- инициальная аббревиация и эллипс (D-ATIS - data link automatic terminal information service);

- инициальная аббревиация и полное слово (CAVOK - ceiling and visibility $\mathrm{OK})$;

- полное слово (служебная часть речи), усечение и эллипс главного слова (NOSIG - no significant change). Сокращение главного слова объясняется его меньшей информативной значимостью в контексте сообщения о прогнозе. 
Сокращения CAVOK и NOSIG можно отнести к переходной группе между собственно графическими и графико-лексическими, так как они употребляются и в письменной, и в устной речи, однако возможность вступать в системные отношения у них отсутствует.

Алфабетизмы представлены двух- и трехкомпонентными инициальными аббревиатурами: $C B$ - сuтulonimbus; RVR - runway visual range. Отдельную группу составляют сокращения так называемого Q-кода: QFE atmospheric pressure at aerodrome elevation; $\mathrm{QNH}$ - altimeter sub-setting to obtain elevation when on the ground.

«Английский язык ... не использует возможность превращения сокращенного слова в акроним, стремясь подчеркнуть информативную нагрузку каждого компонента, входящего в аббревиатуру» [9, с.22]. Английские алфабетизмы дискурсивного поля радиообмена заимствуются другими языками, в частности, русским языком, в которых они функционируют как самостоятельные лексические единицы: ILS - instrument landing system.

Результаты проведенной работы могут быть использованы при исследовании аббревиатурной лексики других типов дискурса, а также найти практическое применение при обучении профессионально ориентированному английскому языку в авиационных вузах.

Учитывая компетентностный подход и коммуникативную направленность языковой подготовки авиационных специалистов, формирование коммуникативной компетенции как цели обучения может произойти при условии моделирования в учебном процессе типовых ситуаций профессиональной деятельности летчика. При этом необходимо обучать речевым действиям, соотносимым в коммуникативном плане с профессиональными функциями специалиста. Такое вовлечение в профессионально значимое общение - ключ к повышению уровня мотивации. Например, при изучении темы «Метеорологическое обеспечение полетов» задание типа «Study the MERAR report and determine present weather with your crewmembers before the flight
METAR KBLV $011657 Z$ AUTO 25015G30KT 210V290 3/8SM R32L/1000FT FG BKN005 01/M01 Q1011» может быть нацелено на: а) закрепление лексического материала (аббревиатуры профессионального языка, лексика по теме), б) формирование навыка связной монологической речи (перевод кодовой формы передачи информации на разговорный язык), в) оформление высказывания в соответствии с требованиями профессионального дискурса (краткость, однозначность), г) использование фоновых знаний. Ожидаемый вариант ответа на данное задание приводится ниже: This is a weather report for the KBLV airport region (Scott Air Force Base/MidAmerica Airport, Belleville, Illinois, USA). It is present weather information for the first day of the month issued at 1657 UTC. It is automated observation. The speed of the wind is 15 knots, gusting to 30 knots. Its direction is 250 degrees magnetic. The direction is varying from 210 to 290 degrees magnetic. Visibility is $3 / 8$ of a statute mile. The runway visual range for runway 32 left is 1000 feet. It is foggy. The cloud base is broken at 500 feet. The temperature is one degree of Celsius above zero; the dew point is one degree of Celsius below zero. The atmospheric pressure is $1011 \mathrm{hPa}$.

Таким образом, проведенный анализ сокращений в метеорологических сообщениях при ведении радиообмена в авиации позволяет сделать следующие выводы:

1. использование аббревиатур в воздушном радиообмене продиктовано характером институционального дискурса;

2. аббревиатурное пространство жанра метеосообщений представлено собственно графическими и графико-лексическими сокращениями;

3. к наиболее распространенным моделям аббревиации можно отнести инициальную модель и усечение, а также их комбинации;

4. использование как кода, так и аббревиаций обеспечивает сочетание информативности, краткости и однозначности высказывания;

5. кодифицированные сообщения о метеообстановке на английском языке имеют большой образовательный потенциал при формировании иноязычной коммуникативной компетенции.

\section{ЛИТЕРАТУРА}

1. Сокращения и коды ИКАО (ICAO Doc 8400). - URL: http://forum.larus.aero/viewtopic.php?t=15 (дата обращения: 2.03.2020).

2. Руководство по авиационной метеорологии» (ICAO Doc 8896 AN/893). - URL: https://studfile.net/preview/6154453/ (дата 0бращения: 2.03.2020).

3. Метеорологическое обеспечение международной аэронавигации. - URL: http://aerohelp.ru/sysfiles/374_11.pdf (дата обращения: 2.03.2020).

4. Борисов В.В. Аббревиация и акронимия. Военные и научно-технические сокращения в иностранных языках / Под ред. А.Д. Швейцера. - М.: Воениздат, 1972. -319 C.

5. Ярмашевич М.А. Аббревиация в современных европейских языках: структурный, семантический и функциональный аспекты: автореф. дис. ... д-ра филол. наук. - Саратов, 2004. - 40 c. - URL: https://static.freereferats.ru/_avtoreferats/01002802672.pdf (дата обращения: 3.04.2020).

6. Красных В.В. Основы психолингвистики и теории коммуникации: Курс лекций. - М.: ИТДГК «Гнозис», 2001. - 270 с.

7. Карасик В.И. Языковой круг: личность, концепты, дискурс - Волгоград: Перемена, 2002. - 477 с. 
8. Голованова Е.И. Профессиональный дискурс, субдискурс, жанр профессиональной коммуникации: соотношение понятий // Вестник Челябинского государственного университета. 2013. №1 (292). Филология. Искусствоведение. Вып. 23. - С. 32-35.

9. Нелюбин Л.Л. Толковый переводческий словарь/ Л.Л. Нелюбин. - 3-е изд., перераб. - М.: Флинта; Наука, 2003. - 320 с.

10. Мальковская Т.А. Англо-русские соответствия в языковой структуре радиообмена в режиме общения пилот - авиадиспетчер: автореферат дис. ... канд. филол. наук: 10.02.20 / Пятигор. гос. лингвист. ун-т - Пятигорск, 2004. - 18 с.

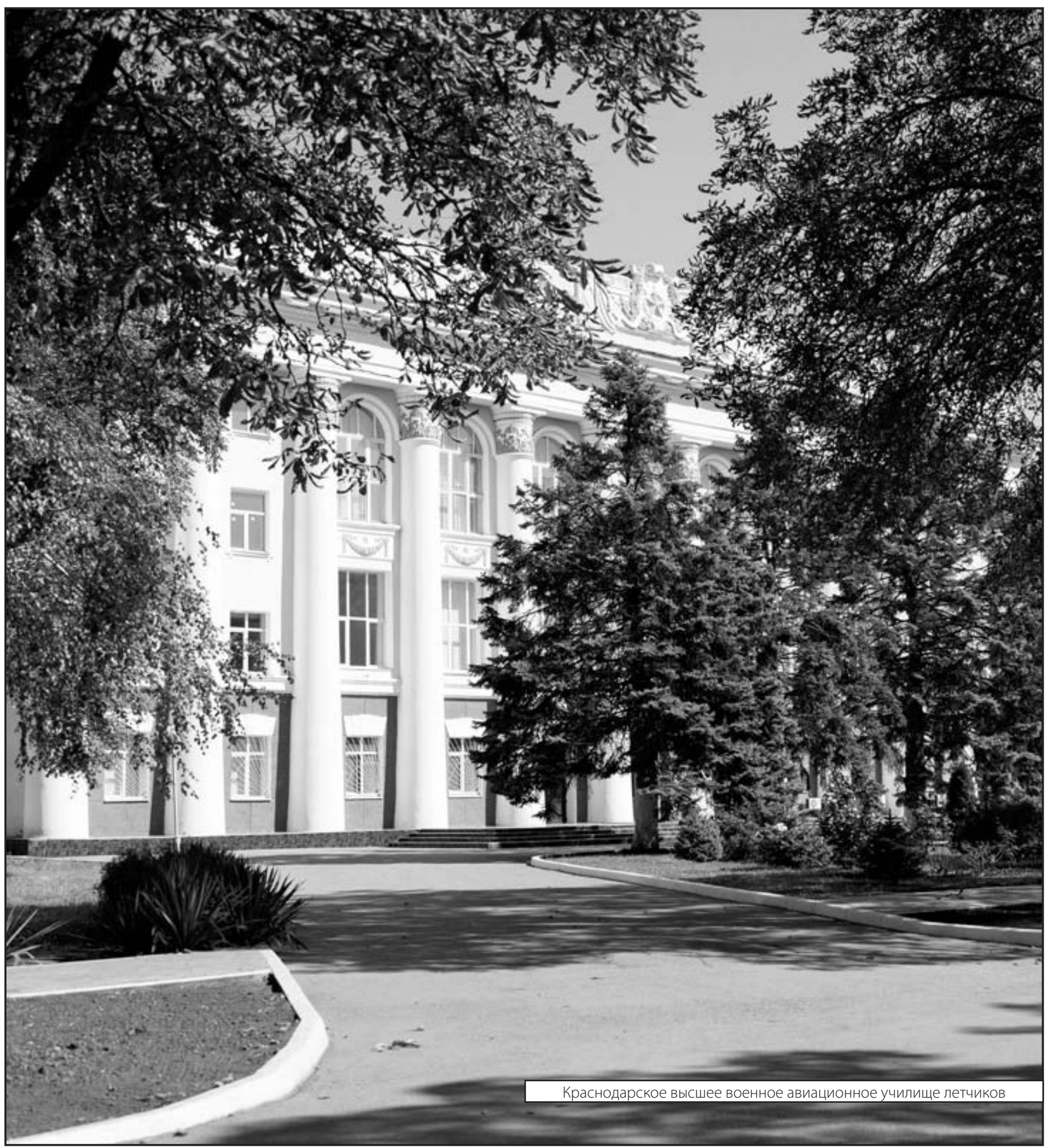

